\title{
A DIMENSÃo POLÍTICA DO GRÊMIO ESTUDANTIL NAS PRODUÇÕES CIENTÍFICAS DOS PROFESSORES DA REDE ESTADUAL DE ENSINO DO PARANÁ
}

\section{THE POLITICAL DIMENSION OF THE STUDENT GRENADIAN IN THE SCIENTIFIC PRODUCTION OF TEACHERS OF THE STATE OF EDUCATION OF PARANÁ}

\author{
Aldimara Catarina Brito Delabona Boutin \\ Universidade Federal de Alfenas (UNIFAL/MG)
}

\section{RESUMO:}

O artigo tem como objetivo abordar sobre a dimensão política dos grêmios estudantis nos artigos produzidos pelos professores do Programa de Desenvolvimento Educacional do Estado do Paraná (PDE/PR). O referencial teórico metodológico que orienta as reflexões é o Materialismo Histórico e Dialético, com a contribuição dos escritos do filósofo marxista italiano Antonio Gramsci. A coleta de dados foi realizada no acervo digital da Secretária do Estado de Educação do Estado do Paraná (SEED/PR), no qual foram localizados 45 artigos, cujo objeto de pesquisa era o grêmio estudantil. Desses artigos, 04 aprofundaram as reflexões sobre a dimensão política dos grêmios. Estruturalmente o artigo está dividido em duas sessões: Na primeira discorre sobre a contribuição dos grêmios estudantis no processo de emancipação política e humana. Em seguida, analisa a dimensão política dos grêmios estudantis nas produções dos professores do PDE. Nas considerações finais, indica que a produção científica dos professores do PDE considera os grêmios como espaços políticos de formação, ressaltando a necessidade de os mesmos desenvolverem ações que contemplem os interesses coletivos.

Palavras chave: grêmio estudantil, dimensão política, participação estudantil, produções do PDE.

\section{ABSTRACT:}

The article aims to address the political dimension of student unions in the articles produced by teachers from the Educational Development Program of the State of Paraná - (PDE / PR). The theoretical and methodological framework that guides the reflections is Historical and Dialectical Materialism, with the contribution of the writings of the Italian Marxist philosopher Antonio Gramsci. Data collection was carried out in the digital collection of the Secretary of State for Education of the State of Paraná - (SEED / PR). 45 articles were found with the object of student council research, of these, 04 deepened the

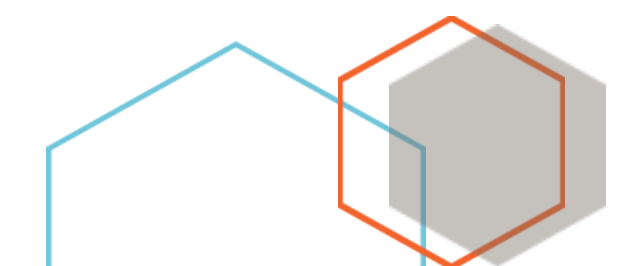

@rquivo Brasileiro de Educação, Belo Horizonte, v. 9, n. 18, 2021 
reflections on the political dimension of the associations. Structurally, the article is divided into two sections: In the first, it discusses the contribution of student unions' political initiatives in the process of political and human emancipation. Then, it analyzes the political dimension of student unions in the productions of PDE teachers. In the final remarks, it indicates that the scientific production of the PDE teachers considers the unions as political training spaces, emphasizing the need for them to develop actions that contemplate the collective interests.

Keywords: student organization, political dimension, student participation, PDE productions.

\section{1- INTRODUÇÃO}

Para Gramsci (2014, p. 406 - 407) “o homem é essencialmente político, já que a atividade para transformar e dirigir conscientemente os outros homens realiza a sua humanidade e a natureza humana”. Isso significa que o mundo e as relações sociais instituídas não são definitivas, ao contrário são constantemente transformadas pela ação humana. É nesse sentido que, a criação de uma realidade superior à que temos demanda o desenvolvimento de uma consciência política que vislumbre os trabalhadores no centro do processo social.

Vásquez (2011) enfatiza que na práxis política, ou seja, aquela que é orientada, organizada e direcionada para a transformação social, o homem amplia seu conhecimento sobre a realidade. Sendo assim, há um caráter educativo na "atividade política", o qual se revela, no “choque de contraposições de ideias, projetos, programas" (VÁSQUEZ, 2011, p. 233) que contemplem iniciativas políticas. Portanto, na ação prática inclinada para o objetivo da transformação da realidade mais imediata em que o ser humano se insere.

Tomando como referência a reflexão em tela, consideramos a dimensão política dos grêmios estudantis, enquanto mecanismos de representação do corpo discente, que possibilitam o aprofundamento da conscientização sobre a realidade social, política e econômica da atual estrutura social. A partir dessa conscientização a organização discente pode ocorrer com vistas ao enfrentamento dos problemas vivenciados no cotidiano escolar, na comunidade ou na realidade social mais ampla.

Este artigo tem como objetivo abordar sobre a "dimensão política" dos grêmios estudantis nas produções ${ }^{1}$ científicas desenvolvidas por professores vinculados ao Programa de Desenvolvimento Estadual - (PDE) do Estado do Paraná.

\footnotetext{
${ }^{1}$ Essas produções constituem artigos científicos resultantes do Projeto de Intervenção Pedagógica na Escola aplicado pelos professores do PDE/PR.
} 
O PDE é uma política estadual normatizada pela Lei complementar n. 130 de 4 de julho de 2010, destinada para professores da rede estadual do Paraná. Esse programa tem como objetivo a capacitação docente, por meio "ingresso anual de professores da Rede Pública Estadual de Ensino para a participação em processo de formação continuada com duração de 2 (dois) anos, tendo como meta qualitativa a melhoria do processo de ensino e aprendizagem nas escolas públicas estaduais de Educação Básica”. (PARANÁ, 2010)

Para participar do PDE, os professores deverão compor o quadro do magistério da rede Estadual de ensino do Paraná, possuir diploma de licenciatura plena e ter cumprido o período de estágio probatório (PARANÁ, 2010). Os estudos e pesquisas desenvolvidas por professores participantes do PDE,

[...] ocorrem em parceria com Instituições Públicas de Ensino Superior, proporcionando ao professor o retorno às atividades acadêmicas de sua área de formação inicial, e devem ser desenvolvidos por meio de atividades teórico-práticas orientadas e definidas a partir das necessidades da Educação Básica, considerando três eixos: a proposta de estudo - desenvolvida ao longo de dois anos, a elaboração de material(is) didático(s) - para uso na escola, e a orientação de Grupo(s) de Trabalho em Rede - que envolve o conjunto dos professores da rede pública estadual. (BIANCO; NONATO JR, 2008, p. 02)

As atividades oferecidas pelo PDE são na modalidade presencial e a distância, sendo que os professores desenvolvem um Projeto de Intervenção Pedagógica na Escola em que estão lotados, o qual é elaborado sobre a supervisão de um professor orientador, vinculado à faculdades ou universidades estaduais paranaenses. (PARANÁ, 2010)

A busca do material empírico que compõe este artigo, foi realizada no banco de produções científicas do PDE, disponível no site da Secretaria do Estado de Educação do Estado do Paraná - (SEED/PR). Para este levantamento, não estabelecemos um recorte temporal específico e selecionamos todos os artigos disponibilizados nesse acervo digital.

Localizamos um total de 45 artigos, produzidos entre os anos de 2008 e 2016. Realizamos a leitura e fichamento desse material com o objetivo de evidenciar debates sobre a dimensão política dos grêmios estudantis. Verificamos que 25 artigos indicaram a dimensão política dos grêmios estudantis, mas não ampliaram as reflexões acerca dessa dimensão, limitando-se a apenas mencionar a existência da mesma.

Somente 4 artigos aprofundaram o debate em torno do caráter político dos grêmios estudantis. Com base nesse material realizamos nossas análises para esse estudo. 
Estruturalmente o artigo está dividido em duas partes. Na primeira destacamos os grêmios estudantis, enquanto espaços formativos que possibilitam o desenvolvimento de ações de caráter político, que contribuem para o aprofundamento da consciência crítica dos jovens e para um posterior processo de emancipação política e humana. Em seguida, analisamos a presença da dimensão política dos grêmios estudantis nos 4 artigos selecionados, a partir do levantamento empírico das produções do PDE.

Por fim, as considerações finais indicamos que embora a maioria dos artigos produzidos pelos professores do PDE, não tenham aprofundado reflexões acerca da dimensão política dos grêmios, 4 artigos moveram-se nesse objetivo. Esses, além de pautaram argumentos na defesa dos grêmios como espaços de formação, debate e desenvolvimento de atitudes políticas, consideram a necessidade de os grêmios desenvolverem ações conciliadas com os interesses sociais coletivos.

\section{2- Considerações sobre a dimensão política do grêmio estudantil}

O grêmio estudantil é uma instância colegiada, ligada ao movimento estudantil, que representa os estudantes do ensino fundamental, médio e técnico de uma instituição de ensino. A organização discente em grêmios estudantis, é garantida por lei ${ }^{2}$ e possui finalidades sociais, culturais e políticas.

Portanto, o grêmio além de dar voz aos estudantes, é um espaço de sociabilidade, que possibilita o debate sobre questões políticas e a organização das demandas e reinvindicações do coletivo dos estudantes e, por isso, também pode ser considerado como um instrumento que viabiliza o desenvolvimento de aprendizados e experiências políticas, permitindo a "discussão de importantes temas referentes à cidadania, inclusive à própria ideia de justiça e igualdade. Ao se pensar na escola, é preciso salientar que o objetivo é a aprendizagem dos alunos. Esta concepção está inserida no conceito de igualdade, ou seja, para todos”. (KAMADA; BRAGA; MARQUES, 2017, p. 201)

Em relação as demandas ${ }^{3}$ realizadas pelos movimentos estudantis, Bringel (2012) aponta que as mesmas podem ser internas e externas. As demandas de caráter interno se referem

\footnotetext{
${ }^{2}$ Em referência a Lei Federal 7.398 de novembro de 1985.

${ }^{3}$ De acordo com Gohn (2008), as demandas dos movimentos sociais são construídas a partir de uma situação de carência ou de privação, a qual pode ser material, política, econômica ou cultural.
} 
as pautas particularizadas aos espaços e instituições nas quais o movimento estudantil está inserido. Já as demandas externas ultrapassam as especificidades locais, sendo mais abrangentes, por se articularem a uma luta maior, ou seja, podem visar a ampliação de direitos para um amplo grupo social. (BRINGEL, 2012)

A articulação entre a pautas específicas e de abrangência geral, bem como também a definição de linhas de ações, objetivos e encaminhamentos das lutas estudantis, são facilitadas quando há uma relação de parceria entre os grêmios estudantis de diferentes instituições de ensino e as demais instituições representativas do movimento estudantil brasileiro, as quais são representadas pelas Uniões Municipais dos Estudantes - (UMES) com sede nos municípios brasileiros, Uniões Estaduais do Estudantes Secundaristas, localizadas nos diferentes Estados do Brasil e pela União Brasileira dos Estudantes Secundaristas - (UBES), que é a entidade que organiza em nível nacional os estudantes secundaristas. (UNE, 2011)

O direito a participação de jovens em grêmios estudantis é garantido por uma legislação específica, a Lei Federal 7.398 de novembro de 1985, batizada de Lei do Grêmio, a qual prevê:

Art. $1^{\circ}$ - Aos estudantes dos estabelecimentos de ensino de $1^{\circ}$ e $2^{\circ}$ graus fica assegurada a organização de Estudantes como entidades autônomas representativas dos interesses dos estudantes secundaristas com finalidades educacionais, culturais, cívicas esportivas e sociais.

$\S 1^{\circ}$ - (VETADO).

$\S 2^{\circ}$ - A organização, o funcionamento e as atividades dos Grêmios serão estabelecidos nos seus estatutos, aprovados em Assembléia Geral do corpo discente de cada estabelecimento de ensino convocada para este fim.

$\S 3^{\circ}$ - A aprovação dos estatutos, e a escolha dos dirigentes e dos representantes do Grêmio Estudantil serão realizadas pelo voto direto e secreto de cada estudante observando-se no que couber, as normas da legislação eleitoral.

Art . $2^{\circ}$ - Esta Lei entra em vigor na data de sua publicação.

Art . $3^{\circ}$ - Revogam-se as disposições em contrário.

Brasília, em 04 de novembro de 1985; $164^{\circ}$ da Independência e $97^{\circ}$ da República. (BRASIL, 1985)

Além de garantir a participação em grêmios estudantis, enquanto um direito dos estudantes, a Lei 7.398/1985 também indica sobre o seu funcionamento e como deve ocorrer a escolha de seus representantes. O Estatuto da Criança e do Adolescente, Lei 8.069 de 13 de julho de 1990, também dispõe sobre o "direito de organização e participação de jovens adolescentes em entidades estudantis" (BRASIL, 1990), dentre as quais o grêmio estudantil se insere.

Cabe destacar que, além da participação discente em entidades representativas ser um direito dos jovens e adolescentes brasileiros, a Lei do Grêmio Livre aponta que a participação discente deve ocorrer de forma autônoma, ou seja, desvinculada das interferências dos sujeitos 
alheios aos grêmios estudantis. Entretanto, para que isso se torne uma realidade, é fundamental que a escola, disponha de suporte físico e pessoal para que os alunos realizem seus projetos e desenvolvam ações sem a intervenção de professores ou gestores, pois conforme destaca Veiga (2007, p. 123) o "grêmio estudantil não é um instrumento de luta contra a direção, mas uma organização onde se cultiva o interesse dos estudantes, onde eles têm possibilidade de democratizar decisões e formar o sentimento de responsabilidade".

Para que a relação entre grêmio, gestão e demais sujeitos que compõe a comunidade escolar contemple os interesses coletivos dos estudantes, é importante que haja o desenvolvimento da autonomia dos alunos. Para as autoras Pavão e Carbelo (2013), isso constitui um aprendizado para além dos muros da escola, conforme destacam no fragmento em destaque:

\begin{abstract}
Atentamos que é importante que o grêmio estudantil seja organizado pelos estudantes e se constitua em espaço de debates, deliberações e encaminhamentos de assuntos de interesse dos estudantes. A atuação do grêmio estudantil não se reduz ao âmbito escolar, ultrapassa os muros da escola, pois uma das finalidades do grêmio é envolver os alunos com o aprendizado das regras da vida em sociedade, promovendo a consciência política. Os estudantes passam a debater direitos e deveres dentro e fora da escola. São essas experiências que contribuem para o aprendizado fundamental de organização política. (PAVÃO; CARBELO, 2013, p. 1.399)
\end{abstract}

O debate político sobre os direitos e deveres e o estímulo à participação discente contribui para o desenvolvimento de aprendizados e experiências que auxiliam para a construção da cidadania, para a análise da conjuntura econômica, social e política em que os jovens se inserem, ou seja, para um processo no qual os jovens podem se emancipar das relações de domínio e subordinação vivenciadas na atual organização societária. Nesse sentido:

[...] ao participarem de grêmios estudantis, os jovens vivenciam a democracia na prática, conhecem seus direitos e deveres e lutam para a conquista de novos direitos dentro da escola e no âmbito da sociedade civil. Essas lutas, geralmente agregam estudantes secundaristas, que sendo oriundos de diferentes realidades, compartilham entre si experiências, projetos políticos, pautas, práticas organizativas e demais saberes. (BOUTIN, 2021, p. 112)

A participação de jovens em grêmios estudantis possui uma dimensão política, a qual se evidencia na medida em que eles compreendem que o papel do grêmio é a luta pelos interesses da maioria dos estudantes e não apenas de um grupo restrito de alunos, professores, gestores ou demais funcionários ligados a escola. Quando a participação contempla as demandas dos discentes, o grêmio se fortalece e ganha representatividade junto aos demais estudantes, pois as ações desenvolvidas são baseadas nos interesses coletivos. A partir disso, a 
participação "situa-se no âmbito da política e oportuniza a vivência da democracia em sua plenitude". (BOUTIN, 2021, p. 110)

De acordo com Gramsci (2014, p. 314) quando há o rompimento com a consciência individual e egoística, estruturada sobre os interesses de pequenos grupos, para ceder lugar uma forma de consciência estruturada nos projetos e interesses coletivos, ocorre o momento denominado de "catarse". Nesse, é evidenciada:

[..] a passagem do momento meramente econômico (ou egoístico passional) ao momento ético-político, isto é, a elaboração superior da estrutura em superestrutura na consciência dos homens. Isto significa também, a passagem do "objetivo ao subjetivo" e da "necessidade a liberdade". (GRAMSCI, 2014, p. 314)

A catarse envolve a compreensão ampliada do mundo e da realidade social, política e econômica presente na sociedade de classes. No momento catártico, as ações e os projetos desenvolvidos contemplam os objetivos da maioria, e desse modo, possuem conotação ético política. A práxis decorrente deste modo fazer política é orientada para a emancipação política e humana, ou seja, é política no sentido que seu objetivo é a transformação social e a criação de uma realidade infinitamente superior a realidade fundamentada no modo de produção capitalista. (VÁSQUEZ, 2011)

De acordo com Vásquez (2011) a práxis política:

[...] pressupõe a participação de amplos setores da sociedade. Persegue determinados fins que correspondem aos interesses radicais das classes sociais, e em cada situação concreta a realização desses fins é condicionada pelas possiblidades objetivas inscritas na própria realidade. Uma política que corresponda a essas possibilidades e que exclua todo o aventureirismo exige um conhecimento dessa realidade e da correlação de classes para não se proporem ações que desemboquem inexoravelmente em um fracasso. A luta tem de ser, portanto, consciente, organizada e dirigida [...]. (VÁSQUEZ, 2011, p. 233)

A práxis política se estabelece no contato com a realidade social mais ampla, a partir do qual, possibilita-se a leitura dos determinantes sociais, culturais, políticos e econômicos, presentes na sociedade de classes, e vislumbra-se a necessidade de encaminhar as lutas no sentido de superá-los. Vásquez (2011, p. 233) afirma que o produto da práxis política é a práxis revolucionária, a qual corresponde a uma "etapa superior da transformação prática da sociedade" pois "permite mudar radicalmente as bases econômicas e sociais em que se assenta o poder material e espiritual da classe dominante e, instaurar assim uma nova sociedade" fundamentada nos interesses sociais coletivos da imensa maioria que é a classe trabalhadora.

A criação de uma nova realidade, portanto, é uma ação pensada, guiada e sistematizada, que decorre da práxis política. Contudo é importante destacar que as alternativas 
revolucionárias desenvolvidas ou que estão em vias de desenvolvimento no modo de produção capitalista são apaziguadas por ideologias impostas pelas classes dominantes. Essas desenvolvem iniciativas cujo objetivo é o "amoldamento" e o "apassivamento" dos segmentos sociais subalternizados (IASI, 2013, p. 72). Isso significa que os trabalhadores "pensam o mundo e a si mesmos a partir dos elementos que constituem a consciência da burguesia" (IASI, 2013, p. 72), pois a classe dominante detém a primazia sobre a produção, divulgação e perpetuação das ideias e concepções que contribuem para a manutenção do seu poder e domínio em toda a sociedade.

A respeito desse debate, Marx e Engels (2007) nos alertam que:

\begin{abstract}
As ideias da classe dominante são, em cada época, as ideias dominantes, isto é, a classe que é a força material dominante da sociedade é, ao mesmo tempo, sua força espiritual dominante. A classe que tem à sua disposição os meios da produção material dispõe também dos meios da produção espiritual, de modo que a ela estão submetidos aproximadamente ao mesmo tempo os pensamentos daqueles aos quais faltam os meios da produção espiritual. As ideias dominantes não são nada mais do que a expressão ideal das relações materiais dominantes, são as relações materiais dominantes apreendidas como ideias; portanto, são a expressão das relações que fazem de uma classe a classe dominante, são as ideias de sua dominação. Os indivíduos que compõem a classe dominante possuem, entre outras coisas, também consciência e, por isso, pensam; na medida em que dominam como classe e determinam todo o âmbito de uma época histórica, é evidente que eles o fazem em toda a sua extensão, portanto, entre outras coisas, que eles dominam também como pensadores, como produtores de ideias, que regulam a produção e a distribuição das ideias de seu tempo; e, por conseguinte, que suas ideias são as ideias dominantes da época. [...]. (MARX; ENGELS, 2007, p. 49)
\end{abstract}

Assim sendo, as ideias que são hegemônicas em determinada conjuntura social ou política não estão desvinculadas da economia. De acordo com Gramsci (2014, p. 94) o domínio de uma classe sobre a outra é viabilizado por meio da "direção intelectual e moral", que se estabelece por meio da sedimentação de ideologias que direcionam para o mesmo "modo de pensar e agir", transformando-se em senso comum, ou seja em uma filosofia homogênea que movimenta ideologicamente homens e mulheres em direção a determinado projeto político.

Para o filósofo sardo, o senso comum é um instrumento político da classe dominante, que contribui para que as ideologias burguesas se transformem em ideias comuns, cooperando para a desmobilização da classe trabalhadora e para a fragmentação de suas lutas. (GRAMSCI, 2014). Portanto:

O senso comum [...] é o "folclore" da filosofia e, como o folclore, apresenta-se em inumeráveis formas; seu traço fundamental e mais característico e o de ser uma concepção (inclusive nos cérebros individuais) desagregada, incoerente, inconsequente, conforme a posição social e cultural das multidões das quais ele e a filosofia. (GRAMSCI, 2014, p. 113) 
A difusão e aceitação de ideias ou concepções de mundo fundamentadas no senso comum em todo o terreno social é facilitada mediante a atividade dos "organismos privados de hegemonia" (GRAMSCI, 2016, p. 121), os quais são representados pelas "organizações ditas privadas como a igreja, os sindicatos e a escola" (LIGUORI, 2003, p. 179), os meios de comunicação de massa e outras instituições que contribuem para a difusão de determinadas visões de mundo, exercendo influência cultural, política e ideológica sobre as camadas populares. (LIGUORI, 2003)

A educação formal, institucionalizada na escola, é uma prática social que não está neutra nesse processo. Para Mészáros (2008, p. 35), a educação que se desenvolve no modo de produção capitalista contribui para a transmissão dos interesses vinculados à classe dominante, na medida em que padroniza os pensamentos e as ações necessárias para a manutenção da sociedade de classes.

Para o autor,

A educação institucionalizada, especialmente nos últimos 150 anos, serviu - no seu todo - ao propósito de não só fornecer os conhecimentos e o pessoas necessário à máquina produtiva em expansão do sistema do capital, como também gerar e transmitir um quadro de valores que legitima os interesses dominantes, como se não pudesse haver nenhuma alternativa à gestão da sociedade, seja na forma 'internalizada' (isto é, pelos indivíduos devidamente 'educados' e aceitos) ou através de uma dominação estrutural e uma subordinação hierárquica e implacavelmente impostas. (MÉSZÁROS, 2008, p. 35)

É por meio da educação gestada e desenvolvida na atual estrutura social que os interesses estratégicos da classe dominante, suas visões de mundo e concepções são sedimentadas em todo o terreno social. Para Cury (2000) isso se explicita na dimensão técnica e na dimensão política assumidas pelo ensino. A dimensão técnica tem como objetivo a formação da mão de obra qualificada para a inserção imediata de homens e mulheres no mercado de trabalho e para a manutenção das estruturas produtivas por meio da produção de bens e mercadorias para a geração da mais valia (CURY, 2000). A dimensão política, visa a transmissão de um conjunto de valores, que são fundamentais para a manutenção da situação de exploração, domínio e submissão que os trabalhadores estão imersos. (CURY, 2000)

Mészáros (2008, p. 35) ressalta a necessidade de superar a lógica capitalista, perseguindo "de modo planejado e consistente uma estratégia de rompimento do controle exercido pelo capital, com todos os meios disponíveis, bem como com todos os meios ainda a ser inventados, e que tenham o mesmo espírito". Por isso, é preciso estimular na geração de jovens, o desenvolvimento de práticas que descontruam essas ideologias e que inspirem a práxis política no interior das instituições de ensino.

@rquivo Brasileiro de Educação, Belo Horizonte, v. 9, n. 18, 2021 
Lenin (2015) no discurso proferido no Terceiro Congresso das Juventudes Comunistas realizado no dia 02 de outubro de 1920, destacou a juventude como um segmento que pode contribuir para a construção de uma sociedade livre da exploração do homem pelo homem. De acordo com o autor:

No tempo que os jovens passam pela escola, esta tem de fazer deles participantes na luta para se libertarem dos exploradores. A União das Juventudes Comunistas somente será digna desse nome, de ser união da jovem geração comunista, se vincular cada passo da sua instrução, educação e formação a participação na luta comum de todos os trabalhadores contra exploradores. Vocês sabem perfeitamente que enquanto a Rússia for a única república operária, e no resto do mundo subsistir o antigo regime burguês, seremos mais fracos do que eles; vocês sabem que estamos constantemente sob ameaça de novos ataques, e que somente aprendendo a manter entre nós a coesão e a unidade triunfaremos nas lutas futuras e, depois que tivermos nos fortalecido, nos tornaremos verdadeiramente invencíveis. Portanto ser comunista significa organizar e unir toda a jovem geração, dar exemplo de educação e de disciplina nessa luta. [...]. (LENIN, 2015, p. 35)

O grêmio estudantil, enquanto instância colegiada que representa o coletivo dos estudantes de uma instituição de ensino e também uma fração dos jovens que estão vinculados aos movimentos estudantis ${ }^{4}$, possui a potencialidade de conciliar suas atividades aos objetivos comprometidos com a realização da práxis política. De acordo com Mandel (1979, p. 48) os estudantes organizados, podem desenvolver processos de lutas, denunciando os limites da sociedade de classes e com isso difundir uma consciência "revolucionária anticapitalista no seio da classe operária".

Mandel (1979) considera que um processo de emancipação humana não ocorre sem a ampliação da consciência da classe trabalhadora e sem o rompimento com as amarras ideológicas que sustentam o modo de produção capitalista, pois:

[...] o grande movimento de libertação da humanidade deve ser guiado por um esforço consciente para reconstruir a sociedade, para ultrapassar uma situação na qual o homem está dominado pelas forças cegas da economia de mercado e começa a tomar as mãos do próprio destino. Este ato consciente de emancipação não pode ser conduzido com eficácia, e muito menos até o fim, sem que o homem tome consciência do ambiente social em que vive, das forças sociais com que deve enfrentar-se e das condições econômicas e sociais gerais desse movimento para a libertação. (MANDEL, 1979, p. 20).

A organização estudantil em grêmios e em instituições representativas do movimento estudantil constitui um modo de desafiar os modos incorporação dos padrões, ideias e práticas que movimentam a sociedade de classes, na medida em que auxilia no processo de compreensão

\footnotetext{
${ }^{4}$ Em referência as demais instituições representativas que compõe o movimento estudantil brasileiro, como as entidades municipais, estaduais e nacional.
} 
dos mecanismos de funcionamento do sistema capitalista e de sua lógica expansiva fundamentada na contradição entre capital e trabalho.

Isso ocorre porque no interior dos grêmios os jovens tomam conhecimento dos problemas vivenciados tanto nas instituições de ensino, vinculada ao grêmio, como também na comunidade ou em toda a sociedade. A partir do conhecimento de tais problemas os jovens podem debatê-los conjuntamente e buscar alternativas visando a sua solução. Essas alternativas muitas vezes passam pela busca do atendimento de direitos já existentes na forma da lei, como também requerem o desenvolvimento de lutas que confrontam o poder instituído e buscam a ampliação dos direitos sociais coletivos.

É importante destacar que o desenvolvimento de lutas ou iniciativas políticas pelos grêmios estudantis, muitas vezes é permeado por dificuldades. A respeito desse debate, as pesquisas de Boutin (2016) e Carlos (2006) evidenciaram a existência de situações ou pessoas que interferem diretamente no engajamento dos alunos em grêmios estudantis nas instituições de ensino.

De acordo com Boutin (2016), os elementos que inibem a participação discente em grêmios estudantis, podem se fazer presentes nas relações interpessoais, estabelecidas entre os alunos, gestores, professores ou demais funcionários da instituição de ensino vinculada ao grêmio. Também pode ser um fator limitador da participação discente em grêmios estudantis, a ausência de materiais ou espaços físicos necessários para o desenvolvimento de ações e projetos políticos. Ainda há de se considerar a condição social ou econômica dos alunos que participam das agremiações, pois conforme Carlos (2006) evidenciou em sua pesquisa de mestrado, o fato de que parte dos alunos está inserida no mercado de trabalho ou a procura de uma atividade remunerada é um entrave à participação discente em grêmios.

Consideramos que o aprofundamento do debate e a reflexão ampliada sobre a importância da organização juvenil em grêmios estudantis, constitui uma das estratégias para superar os condicionantes que por vezes limitam a participação nessa instância colegiada. $\mathrm{O}$ debate em relação ao grêmio não pode estar desvinculado do esclarecimento sobre a sua dimensão política, já que esse é um instrumento de organização e formação política e cultural, que no interior da sociedade burguesa pode se converter em uma alternativa na luta pela emancipação humana.

Na seção que dá sequência a reflexão proposta para este artigo, temos como objetivo analisar as produções científicas dos professores do PDE- PR e a partir disso localizar a dimensão política do grêmio estudantil presente em tais produções. 


\section{3- A dimensão política do grêmio estudantil nas produções dos professores da rede estadual de ensino do Paraná}

A práxis política decorre do conhecimento da realidade, do questionamento do que está estabelecido, naturalizado e solidificado no terreno social e, portanto, envolve conflitos e embates com as relações de hegemonia que imperam em toda a sociedade. Esses embates podem se desenvolver ou estar presentes em diferentes instituições da sociedade civil, como na escola e em espaços que estão sob o controle dos grupos que detém a hegemonia na economia, na política e na cultura. (GRAMSCI, 2016)

O controle da hegemonia é um mecanismo utilizado pelas classes dominantes para a conservação da atual estrutura societária. Por isso, colocar a hegemonia dominante em xeque, significa abrir uma fissura para a materialização de transformações sociais, sejam essas imediatas, em caráter de urgência, ou gerais, ou seja, aquelas pautadas em objetivos estabelecidos a longo prazo.

No processo de lutas pela construção de uma nova realidade, destacamos a necessidade da união dos trabalhadores, enquanto classe, em lutas, ações políticas e projetos conciliados aos interesses coletivos, pois “a união não é só aproximação entre corpos físicos: é comunhão de espíritos, é colaboração de pensamento, é apoio recíproco no trabalho de aperfeiçoamento individual, é educação recíproca e recíproco controle" (GRAMSCI, 2004, p. 212). Por isso, o desenvolvimento da práxis política requer a convergência de forças, o engajamento classista e o compartilhamento de ações que visem objetivos comuns.

Os grêmios estudantis são espaços dotados de dimensões políticas, na medida em que possibilitam a reflexão, o debate e o desenvolvimento de ações ou iniciativas políticas não somente em determinada instituição escolar, mas também na sociedade. Contudo, ao realizarmos as análises do material empírico levantado para esta pesquisa, constatamos que o aprofundamento do debate em relação a dimensão política dos grêmios estudantis, foi desconsiderado nas produções acadêmicas dos professores paranaenses, vinculados Programa de Desenvolvimento Estadual - (PDE).

Verificamos que embora o conjunto da produção científica, desenvolvida pelos professores do PDE, não deixassem de considerar a dimensão política dos grêmios, a maioria não ampliou as reflexões sobre as contribuições das iniciativas políticas desenvolvidas pelos grêmios estudantis, para a formação da juventude e para a materialização de transformações sociais coletivas 
Buscando ilustrar os conteúdos presentes em tais produções, no Quadro 1 sistematizamos o levantamento da produção científica sobre grêmios estudantis dos professores do PDE, contemplando as temáticas e objetivos presentes nos artigos levantados e o total das produções.

Quadro 1- Levantamento das produções científicas sobre o grêmio estudantil no acervo do PDE/PR

\begin{tabular}{|l|l|}
\hline \multicolumn{1}{|c|}{ Levantamento das produções sobre grêmio estudantil no acervo do PDE/PR } & Total \\
\hline Artigos que trouxeram o grêmio estudantil como objeto de análise & 45 \\
\hline Artigos que apontaram para a existência da dimensão política dos grêmios estudantis & 25 \\
\hline Artigos que aprofundaram as reflexões sobre a dimensão política dos grêmios estudantis & 04 \\
\hline
\end{tabular}

Fonte: Dados da pesquisa

Nota: Sistematizado pela autora

Do total de 45 artigos acadêmicos produzidos por professores da rede estadual de ensino do Paraná para o Programa de Desenvolvimento Estadual - (PDE), que apresentaram abordagens sobre o grêmio estudantil, 25 apontaram para sua dimensão política. Contudo, apenas 04 ampliaram os debates ou reflexões acerca dessa dimensão e destacaram as contribuições dos grêmios estudantis para a formação política dos jovens no interior das instituições de ensino.

Este achado de pesquisa, evidencia a invisibilidade do caráter político, desta instância representativa dos alunos, na percepção dos professores da rede estadual de ensino do Estado do Paraná. Porém, é importante destacar que os quatro artigos que conferem ênfase à dimensão política do grêmio estudantil, explicitaram sobre as potencialidades formativas dessa instância colegiada, ressaltando o seu caráter pedagógico no desenvolvimento de aprendizados que subsidiam a formação de uma consciência crítica. De acordo com esses escritos, os grêmios estudantis, são espaços de socialização da cultura política, a qual é fundamental para a compreensão dos mecanismos de funcionamento da atual estrutura da sociedade e para a adoção de ações políticas. (BIANCO; NONATO JR, 2008; PRADO; PERRUDE, 2016; DENKER; WEBER, 2012; SILVA, 2009)

Considerando a dimensão política dos grêmios estudantis e a necessidade da organização discente tendo em vista o desenvolvimento de sua dimensão política, o artigo de Bianco e Nonato JR (2008) ressalta que as manifestações políticas dos alunos podem se expressar nos diferentes contextos e práticas desenvolvidas nas escolas, como por exemplo durante uma aula, em seminários, debates, apresentação de trabalhos orais, entre outros. Entretanto para os autores, é no grêmio estudantil que as lideranças são formadas e que se exerce o caráter educativo da participação, conforme expressam por meio do exposto: 
O Grêmio é o espaço apropriado para a aprendizagem do por que, para quê, como e com quem na participação social, sendo o local de desenvolvimento da consciência crítica que permite refletir sobre os erros e acertos nas relações sociais, políticas, educacionais e de poder que se estabelecem dentro das escolas, é experimentando o uso da voz e da vez e a respeitar os outros que se efetiva a participação condição necessária ao processo de democracia. (BIANCO; NONATO JR, 2008, p. 17, grifos dos autores)

A partir das reflexões presentes no fragmento em destaque, podemos compreender os grêmios estudantis como espaços de contestação das relações instituídas na escola e na sociedade, os quais facilitam o desenvolvimento de aprendizados e ampliam as possibilidades de participação dos jovens na tomada de decisões e na construção de projetos coletivos na escola e, por isso possuem uma dimensão política.

Bianco e Nonato JR (2008) ainda acentuam que, para que a escola cumpra a sua dimensão política, é necessário que a mesma resgate nos alunos a sua capacidade de mobilização, preparando-os para a "tomada de decisões e participação coletiva" (BIANCO; NONATO JR, 2008, p. 18) em instâncias de participação discente como o grêmio estudantil. Com base nesse entendimento, compreendemos o grêmio estudantil como um mecanismo de participação, cuja potencialidade é "forjar um bloco intelectual-moral” (GRAMSCI, 1978, p. 20), que torna "politicamente possível um progresso intelectual de massa e não apenas de pequenos grupos intelectuais".

Ao abordarem sobre o conceito de grêmio estudantil, Prado e Perrude (2016) não perderam de vista a dimensão política dessa instância colegiada:

Grêmio Estudantil é uma instância colegiada de representação máxima dos estudantes na escola e seu principal objetivo é fomentar a discussão entre os estudantes de seus deveres e direitos fortalecendo o processo pedagógico e permitindo a construção de um espaço privilegiado de aprendizagem, cidadania, convivência, responsabilidade e de luta por direitos dentro do princípio da gestão democrática, inclusive em torno da comunidade escolar. (PRADO; PERRUDE, 2016, p. 05)

O grêmio estudantil, na perspectiva em tela, se converte em um espaço singular de luta pela conquista, ampliação e gozo de direitos, os quais podem ser de ordem particular (restritos aos espaços em que os grêmios se inserem) ou então podem ultrapassar os muros escolares, contemplando os interesses da comunidade situada no entorno da escola, ou ainda de uma classe social inteira. Prado; Perrude (2016) ampliam a reflexão sobre a dimensão política dos grêmios estudantis argumentando que a conscientização e a inquietação com os problemas vivenciados se constroem na luta, na participação e na organização no interior das agremiações.

Assim sendo, 
$\mathrm{Na}$ participação do Grêmio Estudantil os estudantes devem se inquietar com os problemas do cotidiano ao seu redor e unir-se para pensar alternativas e soluções para os problemas na escola, objetivando efetivar a sua participação na gestão democrática da instituição escolar. No processo de formação da agremiação estudantil os interessados são inicialmente desafiados a organizarem-se para sua fundação, mobilizando os demais alunos e negociando com professores, equipe diretiva e pedagógica da escola. A participação dos estudantes, em especial no Grêmio Estudantil, está intimamente ligada ao processo de aprendizagem que vai sendo construído na prática e nas atividades cotidianas dentro da escola. (PRADO; PERRUDE, 2016, p. 20)

É claro que um grêmio estudantil, pautado em tal objetivo, não significa que os jovens devam deixar de realizar eventos culturais, festivos ou esportivos. Contudo, Prado e Perrude (2016, p. 17) ressaltam a importância de não perder de vista os grêmios estudantis como espaços privilegiados de promoção da cidadania, da "democracia" e da "ética", que auxiliam para o desenvolvimento da "consciência crítica e política".

O desenvolvimento da consciência política, para Gramsci (1978. p. 21), se efetiva na luta por "hegemonias políticas, de direções contrastantes". Para o autor, a "consciência de fazer parte de uma determinada força hegemônica (isto é, a consciência política) é a primeira fase de uma ulterior e progressiva autoconsciência" que superou o senso comum. Denker e Weber (2012, p. 13) avaliam que a perspectiva política dos grêmios estudantis se desenvolve a partir do momento que os alunos se vislumbram como sujeitos de direitos e que entendem as funções e potencialidades da organização discente, pois sendo o grêmio estudantil "um órgão de representação do corpo discente da escola; ele deve representar a vontade coletiva dos estudantes e promover a ampliação da democracia, desenvolvendo a consciência crítica".

O artigo de Silva (2009) destaca o desenvolvimento da consciência crítica como um processo decorrente da formação política, a qual está relacionada com a capacidade de compreensão da organização e dos mecanismos de funcionamento da sociedade capitalista. Nesse sentido, para o autor "o grêmio não pode ser entendido como um órgão simples de representação dos alunos" (SILVA, 2009, p. 9), mas um mecanismo que viabiliza a compreensão das contradições da sociedade de classes e, tendo isso, como premissa, a participação estudantil deve ser "contínua", atuante, engajada e "contemplar os interesses coletivos" (SILVA, 2009, p. 9).

Em face a existência de entraves de ordem política, ideológica, material e institucional, que dificultam a organização discente em grêmios estudantis no interior das instituições de ensino, é necessário ressaltar a importância do desenvolvimento de iniciativas pautadas na formação e implementação de grêmios estudantis nas escolas, pois: 
[...]. Formar um Grêmio é estabelecer um direito humano, porque o Grêmio é uma associação política importantíssima para a realização dos sonhos e projetos dos alunos. Daí a importância de lutarmos por sua efetivação, ou seja, trabalhar com persistência pela formação do Grêmio, exercendo nossa cidadania participativa, a única verdadeiramente transformadora da sociedade que vivemos. Em outras palavras, isso significa que não basta termos direitos, precisamos lutar para torná-los realidade, isso é, efetivá-los. (SILVA, 2009, p. 8)

Nas ações desenvolvidas para organização e implantação de grêmios estudantis nas escolas ou mesmo em atividades realizadas pelas agremiações já constituídas, é possível evidenciar a presença da cidadania política. Desde a montagem de chapas para concorrer nas eleições e, em todo o processo eleitoral dos grêmios, os alunos podem experimentar aprendizados que ultrapassam os currículos formais de ensino. As negociações, as alianças realizadas, as táticas políticas, os debates, as argumentações, a idealização de propostas e os projetos a serem desenvolvidos, são ações que exigem a "disciplina política" (GRAMSCI, 2004, p. 87), fornecem “a vida uma finalidade" (GRAMSCI, 2004, p. 87), e possibilitam a vivencia da práxis política em sua essência.

De acordo com Gramsci (2004, p. 87) "associar-se a um movimento significa assumir uma parte da responsabilidade pelos eventos que estão sendo preparados, tornar-se artífice direto destes mesmos eventos". Para esse autor a participação dos jovens em movimentos juvenis é um ato libertador, que propicia o desenvolvimento de experiências e aprendizados, nos quais se situa a "disciplina política" (GRAMSCI, 2004, p. 87). Tais aprendizados são essencialmente importantes para a práxis alinhada às transformações societárias.

Embora a maioria das produções dos professores do PDE não tenha aprofundado as reflexões sobre a dimensão política dos grêmios estudantis, os 04 artigos que realizaram essa empreitada, apontaram elementos essenciais para a materialização de práticas de caráter político no interior dos grêmios estudantis, destacando a importância do respeito da autonomia dos grêmios estudantis, da reflexão e debate sobre a realidade social, econômica e política em que os jovens se inserem.

Percebemos que as produções que analisaram o caráter político dos grêmios, defenderam o desenvolvimento de ações que superem o caráter local em que as agremiações se inserem e, principalmente que essas ações se desenvolvam levando em consideração o interesse do conjunto de estudantes e não dos outros sujeitos inseridos no contexto escolar. Também foi possível evidenciar que os artigos em questão jogaram luz na necessidade de dar voz aos jovens para que esses possam ser vistos como sujeitos de direitos e que podem e devem pautar suas reivindicações. 


\section{CONSIDERAÇÕES FINAIS}

A participação dos jovens em grêmios estudantis, talvez seja a primeira experiência política da maioria dos estudantes brasileiros. No interior dessa instância colegiada de representação discente, a juventude, aprende o sentido do ato de fazer política, e a partir disso, pode se organizar e debater as demandas estudantis, transformando o espaço escolar em um espaço de luta.

Por isso é importante incentivar a participação da juventude nos grêmios estudantis e fomentar o debate sobre a dimensão politica que permeia esse canal de representação discente. Consideramos que as experiências que decorrem da participação de alunos em grêmios estudantis, instrumentalizam a percepção das relações hierárquicas, concentradoras do poder, de mando e submissão que podem estar presentes tanto em uma instituição escolar, como também toda a sociedade. A partir dessa percepção os jovens podem se organizar em lutas ou iniciativas que busquem o rompimento com tais situações.

Ao analisarmos as produções dos professores do PDE, constatamos que a maioria dos artigos que elegeram o grêmio estudantil como objeto de pesquisa, consideraram a sua dimensão política. No entanto, apenas 04 artigos aprofundaram o debate sobre essa dimensão. Embora, esse dado expresse a invisibilidade do caráter político dos grêmios na visão dos professores, ressaltamos a potencialidade das reflexões desenvolvidas pelos artigos analisados, os quais além de pautarem argumentos na defesa dos grêmios como espaços de formação, debate e desenvolvimento de ações políticas, consideraram a necessidade de os grêmios desenvolverem ações que contemplem os interesses coletivos estudantis ou então da comunidade na qual as agremiações se inserem.

Por isso, esses artigos podem contribuir para o adensamento das reflexões sobre a práxis política estudantil enquanto um dos caminhos que conduzem para a emancipação política e humana, pois "pode -se dizer que nenhum movimento real adquire consciência de seu caráter totalitário de um só golpe, mas apenas por experiências sucessivas, isto é, quando percebe através dos atos que nada do que existe é natural”. (GRAMSCI, 2016, p. 333).

\section{REFERÊNCIAS}

BIANCO, A. A.; NONATO JR, R. A contribuição do grêmio estudantil para o exercício da gestão democrática. In: O Professor PDE e os desafios da escola pública paranaense. Curitiba: PDE, 2008. p. 01-42. 
BOUTIN, A. C. B. D. Grêmio estudantil e participação do estudante: limites e possibilidades para o processo de emancipação em comunidades de periferias da cidade de Ponta Grossa, PR. 2016, 155 f. Dissertação (Mestrado em Educação) - Universidade Estadual de Ponta Grossa, Ponta Grossa, 2016.

BOUTIN, A. C. B. D. Contribuições do grêmio estudantil para a formação discente. In: SILVA, A. M.; PEREIRA, A. L.; SANT'ANA, C. de C.; GABRIEL, F. A. (Orgs). Docência: processo do ensinar e do aprender, vol. 5. São Carlos: Pedro e João editores, 2021. p. 97-114.

BRASIL, Lei Federal, no 7.398, de 04 de novembro de 1985. Disponível em: < http://www.planalto.gov.br/ccivil_03/Leis/L7398.htm > Acesso em: 13 jan. 2019.

BRASIL, Lei Federal no 8.069 de 13 de julho de 1990. Estatuto da Criança e do Adolescente. Disponível em: < http://www.planalto.gov.br/ccivil_03/LEIS/L8069.htm > Acesso em: 13 jan. 2019.

BRINGEL, B. Ciclo de protestos e lutas estudantis no Brasil. Perspectiva histórica, Salvador, n. 02, p. 29-44, jan./jun. 2012.

CARLOS, A. G. Grêmio estudantil e participação do estudante. 2006,118 f. Dissertação de mestrado (Mestrado em educação política e sociedade) - Pontifícia Universidade Católica de São Paulo, São Paulo, 2006.

CURY, J. C. R. Educação e contradição: elementos metodológicos para uma teoria crítica do fenômeno educativo. São Paulo: Cortez, 2000.

DENKER, I. R. M.; W. A. Estatuto da criança e do adolescente: uma oportunidade dos alunos exercerem política na escola através do grêmio estudantil. In: O Professor PDE e os desafios da escola pública paranaense. Curitiba: PDE, 2012. p. 01-18.

GOHN, M da. G. Teorias dos movimentos sociais: paradigmas clássicos e contemporâneos. São Paulo: Edições Loyola, 2008.

GRAMSCI, A. Escritos políticos, vol. I. Rio de Janeiro: Civilização brasileira, 2004.

GRAMSCI, A. Cadernos do cárcere, vol. 3. Rio de Janeiro: Civilização Brasileira, 2016. GRAMSCI, A. Cadernos do cárcere, vol. 1: introdução ao estudo da filosofia, a filosofia de Benedetto Croce. Rio de Janeiro: Civilização Brasileira, 2014.

GRAMSCI, A. Concepção dialética da história. Rio de Janeiro: Civilização Brasileira, 1978.

IASI, M. Educação e consciência de classe: desafios estratégicos. Perspectiva, Florianópolis, v.31, n. 1, p. 63-83, jan./abr. 2013.

KAMADA, M. Y.; BRAGA, C. P.; MARQUES, D. V. Grêmio estudantil: uma constante busca democrática. In: VARANI, A. et al. Seminário avaliação da escola pública sob o viés da qualidade social. Campinas: [Anais eletrônicos]...2017. Disponível em: https://www.researchgate.net/profile/Daniel-Maldonado 2/publication/314246075_Inovacao_pedagogica_nas_aulas_de_Educacao_Fisica_da_escola _publica_brasileira/links/58bdd7ff45851591c5e9ba0a/Inovacao-pedagogica-nas-aulas-deEducacao-Fisica-da-escola-publica-brasileira.pdf\#page=202>. Data de acesso: 14 abr. 2021. 
LENIN, V. I. As tarefas revolucionárias da juventude. São Paulo: Expressão popular, 2015.

LIGUORI, G. Estado e sociedade civil: entender Gramsci para entender a realidade. In: COUTINHO, C. N.; TEIXEIRA, A. P. (Orgs). Ler Gramsci, entender a realidade. Rio de Janeiro: Civilização Brasileira, 2003. p. 173-189.

MANDEL, E. Os estudantes, os intelectuais e a luta de classes. Lisboa: Antídoto, 1979.

MARX, K.; ENGELS, F. A ideologia alemã. São Paulo: Boitempo, 2007.

MÉSZÁROS, I. Educação para além do capital. São Paulo: Boitempo, 2008.

PARANÁ. Lei Complementar 130 de 14 de julho de 2010. Casa Civil do Governo do Estado do Paraná. Curitiba, 2010.

PARANÁ. Secretaria da educação. PDE - Programa de Desenvolvimento Educacional. Curitiba: SEED on line, 2021. Disponível em:

<http://www.gestaoescolar.diaadia.pr.gov.br/modules/conteudo/conteudo.php?conteudo=20

>. Data de acesso: 14 abr. 2021.

PAVÃO, G. C.; CARBELLHO, S. R. Grêmio estudantil: uma instância colegiada em debate. In: XI CONGRESSO NACIONAL DE EDUCAÇÃO (EDUCERE), 2013, Curitiba. Anais... Curitiba: PUC, 2013, p. 1387-1401. Disponível em:

<http://educere.bruc.com.br/arquivo/pdf2013/10217_6140.pdf>. Data de acesso: 10. fev. 2019.

PRADO, A. A.; PERRUDE, M. R da S. Grêmio estudantil: uma proposta de participação política e democrática na escola. In: O Professor PDE e os desafios da escola pública paranaense na perspectiva do professor do PDE. Curitiba: PDE, 2016. p. 01-24.

SILVA, S. A. Uma alternância a barbárie: formação continuada para os grêmios estudantis. In: O Professor PDE e os desafios da escola pública paranaense na perspectiva do professor do PDE. Curitiba: PDE, 2009. p. 01-15.

UNE - União Nacional dos Estudantes. Estrutura do Movimento Estudantil. São Paulo: UNE, 2011. Disponível em: <https://www.une.org.br/2011/09/estrutura-do-movimentoestudantil/\#: :text=Se\%20organiza\%20basicamente\%20a\%20partir,reunindo\%20todas\%20 as\%20entidades\%20e>. Data de acesso: 24 de jun. de 2020.

VÀSQUEZ, A. S. Filosofia da práxis. São Paulo: Expressão Popular, 2011.

VEIGA, Z. de P. A. As Instâncias Colegiadas da Escola. In: VEIGA, I. P. A; RESENDE, L. M. G de. (Orgs.). Escola: espaço do projeto político-pedagógico. Campinas: Papirus, 2007. (p. 113-126).

\section{SOBRE A AUTORA}

Aldimara Catarina Brito Delabona Boutin. Doutora em Educação pela Universidade Estadual de Ponta Grossa (UEPG). Mestre em Educação pela Universidade Estadual de Ponta Grossa (UEPG). Graduada em História pela Universidade Estadual de Ponta Grossa (UEPG). Membro 
do Grupo de Pesquisa Capital, Trabalho, Estado e Educação: Políticas Educacionais e Formação de Professores. Suas pesquisas concentram-se na linha de História da Educação e Política Educacional, com ênfase em Movimento Estudantil. Email: audiboutin@hotmail.com

Tramitação:

Recebido em 30/11/2019

Aprovado em 14/04/2021 